\author{
PHILLIP CAGAN
}

Columbia University

WILLIAM FELLNER

American Enterprise Institute

\title{
Tentative Lessons from the Recent Disinflationary Effort
}

Disinflation, after an extended period of inflationary demand policy such as the United States has experienced, entails costs in a particular sense. The process inevitably leads the economy through several years of weaker "real" performance than that which can be expected for corresponding phases of the business cycle after an adjustment period. This cost of disinflation arises partly because, at the stage of the inflationary process at which the Western countries have arrived in recent decades, large payment commitments still continue to be denominated in the domestic currency. These commitments are made in anticipation of a further deterioration in the currency (whereas, in what is usually described as hyperinflation, the public has already largely turned away from using the domestic currency). Another important reason why in the present circumstances adjustment difficulties are inevitable is that, even if the authorities do have the determination to remain firmly on the disinflation course, it takes time to establish the credibility of that policy. Thus those who are convinced that policies are ill-conceived when based on an alleged long-run "Phillips trade-off"' between inflation and unemployment should be aware of a short-term trade-off: avoidance of the long-run disaster, which continued and accelerating inflation would bring about, causes underutilization and other adjustment difficulties during a disinflationary transition period.

The empirical research summarized here owes much to collaboration with Maryam Homayouni of the American Enterprise Institute. 
In the current disinflation since 1980 the economy has undergone two recessions and considerable disruption of financial markets. The overall decline in economic activity in the second recession of 1981-82 was on a par with the decline in 1973-75, though capacity utilization remained at lower levels longer in the recent recession. Nevertheless, the deceleration of wages has been dramatic, resulting in an overall decline by 1983 that exceeded the 1973-75 decline. Because wages are the major part of unit costs of production, they are the key to a sustainable deceleration of the underlying rate of inflation. A general impression has formed that the response of wages to the recent economic pressures has been greater than was implied by past behavior.

To subject this impression to a quantitative examination, we compared the recent deceleration of wages with its past behavior as described by a wage equation of the conventional type. In the conventional framework wage increases are described mainly by three variables: unemployment, the change in unemployment, and the past rate of inflation. ${ }^{1}$ We fitted the conventional form of the wage equation to quarterly data to determine whether, in recent years, a greater moderation of wage increases has occurred than was indicated by the equations traditionally employed.

The wage equation can be expressed as

$$
w=a_{1}+a_{2} 1 / U+a_{3} \Delta 1 / U+a_{4} p(\text { lagged })+\text { dummy variables },
$$

where $w$ is the percentage rate of change in a wage index, $1 / U$ is the reciprocal of the civilian unemployment rate, $\Delta 1 / U$ is the change in the unemployment reciprocal since the previous quarter, $p$ (lagged) is the percentage rate of change of the price level over previous quarters (which serves as a proxy for market adjustments to rising prices), and dummy variables allow for shifts that would otherwise take place. The $a_{i}$ are constant regression coefficients. The reciprocal of unemployment is used to reflect an assumed convexity in the magnitude of the effect of unemployment on wages. ${ }^{2}$

1. See, for example, George L. Perry, "Inflation in Theory and Practice," BPEA, 1:1980, pp. 207-41; and Otto Eckstein and James A. Girola, "Long-Term Properties of the Price-Wage Mechanism in the United States, 1891 to 1977," Review of Economics and Statistics, vol. 60 (August 1978), pp. 323-33.

2. The Bureau of Labor Statistics, which is the source of the data, has published only an annual version of the wage series for the pre-1964 period. Before the latter annual extension became available, a quarterly series for pre-1964 years was constructed by 
The dummy variables are set at unity for the period indicated and zero otherwise. They record changes in the intercept term relative to the period of the omitted dummy. Thus for the first regression (equation 1) the intercept term was 2.9 percentage points lower in 1960-69 than in 1974-80; it rose from - 2.9 in 1960-69 to - 1.0 in 1970-73; and rose again by 1.0 point from $1970-73$ to $1974-80$. The shifts that the relation has undergone when the dummy variables are disregarded have presumably resulted from changes in price expectations, structural changes in the labor force affecting unemployment, and wage controls or guidelines. The dummy variables therefore reflect the longer-run influences on wage changes from cycle to cycle.

Figure 1 presents postsample simulations since 1980:2 for equations 1 and 2 in table 1 that were fit for the 1953:3 to 1980:1 period. These two regressions differ in the lag with which past price increases are assumed to influence current wage increases. Some studies use the average inflation rate for the year ending one quarter before the current one, which is the practice followed in equation 1 . But one year may be too short to cover the past inflation rate to which wages respond; furthermore, the one-year inflation rate can spuriously reflect recent wage changes or other cyclical variables that may be correlated with the dependent variable. To assess an alternative formulation that partially avoids these difficulties, the inflation variable in equation 2 is an average of the three years ending one quarter before the current year. In table 1, $p_{-1}^{(4 Q)}$ denotes the average inflation rate according to the CPI-U index for the four quarters ending one quarter before the current quarter of the dependent variable, while $p_{-1}^{(12 Q)}$ denotes the analogous term for the twelve quarters ending in the previous quarter.

It is the deviations of the actual changes (also shown in figure 1) from the simulation values that suggest a shift in this relation; in this case it is a downward shift that began in 1981:4.

To test for the significance of these recent deviations, table 1 also presents the equations fit through 1983:2, with a dummy variable added for 1981:4 and afterward. Equation 3 shows that the wage changes for this period average 1 percentage point a year lower than in 1974-80 (to

Robert J. Gordon ("Inflation in Recession and Recovery," BPEA, 1:1971, pp. 105-58, appendix C), which Perry used and kindly made available to us. We adjusted it to conform to the new BLS annual series. The adjustment is not major, and the results are essentially the same using the Gordon series without the adjustment. 
Figure 1. Actual and Predicted Wage Increases, 1980:2 to 1983:2

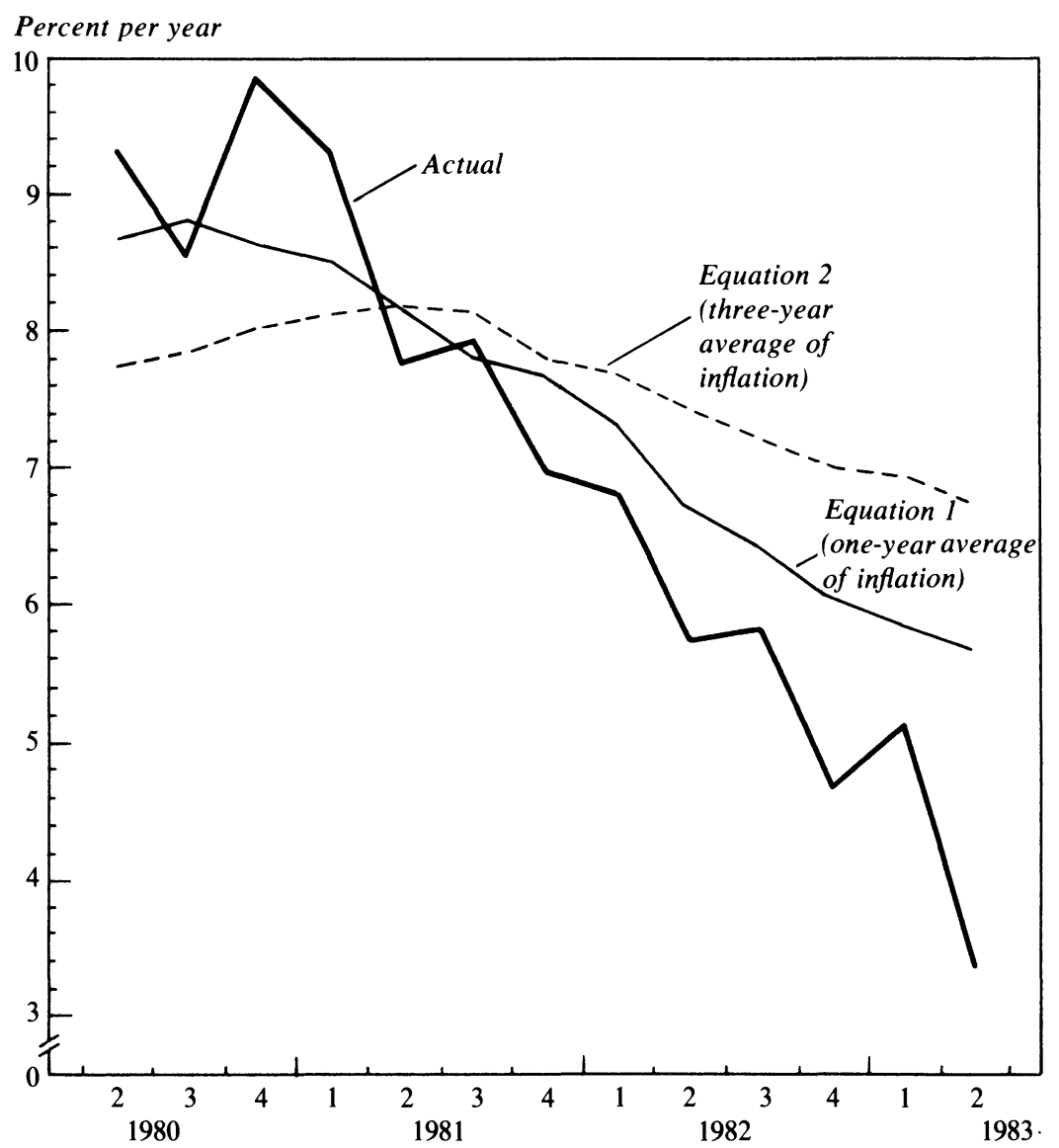

Source: Table 1.

which the significant $t$-statistic pertains) and 1.2 point lower than in 1980-81. In equation 4 a dummy is added for all reference-cycle contractions, which allows for the possibility that the deviations are typically negative during such phases of the business cycle. This does not significantly affect the results. Other equations presented in a more detailed paper we have written point in the same direction. ${ }^{3}$

We are aware that these indications of a recent downward shift in the

3. Phillip Cagan and William Fellner, "The Cost of Disinflation, Credibility, and the Deceleration of Wages 1982-83," Contemporary Economic Problems 1983-84 (Washington: American Enterprise Institute, forthcoming). The regressions in that paper do not include the second quarter of 1983. 
Table 1. Wage-Change Equations, Selected Periods, 1953:3 through 1983:2a

\begin{tabular}{|c|c|c|c|c|}
\hline \multirow[b]{2}{*}{ Item } & \multicolumn{2}{|c|}{ 1953:3-1980:1 } & \multicolumn{2}{|c|}{$1953: 3-1983: 2$} \\
\hline & Equation 1 & Equation 2 & Equation 3 & Equation 4 \\
\hline \multicolumn{5}{|l|}{$\begin{array}{l}\text { Constant and inde- } \\
\text { pendent variable }\end{array}$} \\
\hline Constant & $3.1(5.5)$ & $3.4(4.1)$ & $2.9(5.6)$ & $2.9(5.6)$ \\
\hline $1 / U$ & $15.8(6.2)$ & $18.8(7.2)$ & $15.4(6.2)$ & $15.4(6.2)$ \\
\hline$\Delta 1 / U$ & $12.4(2.3)$ & $8.4(1.5)$ & $12.9(2.5)$ & $12.1(1.7)$ \\
\hline$p_{-1}^{(4 Q)}$ & $0.3(4.1)$ & $\cdots$ & $0.3(5.2)$ & $0.3(5.2)$ \\
\hline$p_{-1}^{(12 Q)}$ & $\cdots$ & $0.2(1.7)$ & $\cdots$ & $\cdots$ \\
\hline \multicolumn{5}{|l|}{$\begin{array}{c}\text { Dummy for } \\
\text { individual } \\
\text { cycles }^{\mathrm{b}}\end{array}$} \\
\hline $1953: 3-1957: 3$ & $-2.3(-3.4)$ & $-3.4(-4.0)$ & $-2.1(-3.3)$ & $-2.1(-3.3)$ \\
\hline $1957: 4-1960: 2$ & $-2.4(-4.3)$ & $-3.2(-4.6)$ & $-2.2(-4.3)$ & $-2.2(-4.3)$ \\
\hline $1960: 3-1969: 4$ & $-2.9(-5.3)$ & $-3.7(-5.0)$ & $-2.7(-5.4)$ & $-2.7(-5.3)$ \\
\hline 1970:1-1973:4 & $-1.0(-2.4)$ & $-1.6(-3.4)$ & $-0.9(-2.2)$ & $-0.9(-2.2)$ \\
\hline 1974:1-1980:1 & c & c & c & c \\
\hline $1980: 2-1981: 3$ & $\cdots$ & $\cdots$ & $0.2(0.5)$ & $0.2(0.5)$ \\
\hline Cycle contractions & $\cdots$ & $\cdots$ & $\cdots$ & $-0.05(-0.2)$ \\
\hline $\begin{array}{l}\text { Recent period: } \\
1981: 4 \text { to } 1983: 2\end{array}$ & $\cdot$ & . & $-1.0(-2.5)$ & $-0.9(-2.1)$ \\
\hline Summary statistic & & & & \\
\hline $\begin{array}{l}\mathbf{R}^{2} \\
\text { Standard error of }\end{array}$ & 0.78 & 0.75 & 0.80 & 0.80 \\
\hline estimate & 0.90 & 0.96 & 0.88 & 0.88 \\
\hline Durbin-Watson & 2.00 & 1.80 & 1.99 & 1.99 \\
\hline
\end{tabular}

Source: Authors' estimates based on data from the U.S. Bureau of Labor Statistics.

a. The dependent variable is the rate of change in the average hourly earnings index; $U$ is the civilian unemployment rate; and $p$ is the rate of change in the consumer price index with the lag structure described in the text. The rates of change are measured as the difference in logs. The numbers in parentheses are $t$-statistics.

b. From the quarter after the reference peak, as calculated by the National Bureau of Economic Research, to the quarter of the next peak.

c. Omitted dummy.

relation do not add up to what one would consider a "proof." For example, the deviations shown in the figure come from equations in which $w$ is a linear function of $1 / U$ rather than of $U$, and it is possible to argue that, although postulating linearity of the function in $U$ itself would be exceedingly unconvincing at very low unemployment rates, the same charge can be made against linearity in $1 / U$ at very high unemployment rates. ${ }^{4}$

4. To the extent that $U$ or $1 / U$ determines $w$, linearity in $U$ would suggest a finite $w$ even at $U=0$, and linearity in $1 / U$ suggests no negative $w$ at any $U$ (regardless of how high the latter is). These are unconvincing suggestions. 
Yet shifting at some arbitrarily chosen value of $U$ from linearity in $1 / U$ to linearity in $U$ would hardly be a commendable procedure, and we do not see any way of avoiding arbitrariness in trying to find a function that in low ranges of $U$ gives results similar to linearity in $1 / U$ and in high ranges of $U$ gives results similar to linearity in $U$.

We interpret the series of dummy variables in equations 3 and 4 of table 1 as strengthening the impression that the relation between wage changes and unemployment and past inflation shifted toward larger wage changes in the 1970-73 cycle and again in the 1974-80 cycle. It remained about the same in the short 1980-81 cycle and then shifted downward from 1981:4 to the present.

Although such shifts are measured here as changes in the intercept of the equation, they could reflect changes in the coefficient of unemployment, of past inflation, or both. Further evidence is needed to determine which. The former would mean that the response of wages to unemployment had intensified in the recent period, and the latter would mean that the response to past inflation had intensified. We are inclined to believe that such shifts reflect responses to the policy environment in which credibility plays an important role, though other special influences cannot be ruled out. Whether credibility is affected by announcements as well as perceived changes in policy actions may be debated, but recent experience points to the importance of policy performance. 